American Journal of Infectious Diseases 5 (3): 170-179, 2009

ISSN 1553-6203

(C) 2009 Science Publications

\title{
Growth Inhibition of Struvite Crystals in the Presence of Herbal Extract Boerhaavia diffusa Linn
}

\author{
${ }^{1}$ C.K. Chauhan, ${ }^{2}$ M.J. Joshi and ${ }^{3}$ A.D.B. Vaidya \\ ${ }^{1} \mathrm{H}$ and HB Kotak Institute of Science, Dr Yagnik Road, Rajkot-360 001, Gujarat, India \\ ${ }^{2}$ Crystal Growth Laboratory, Department of Physics, \\ Saurashtra University, Rajkot-360 005, Gujarat, India \\ ${ }^{3}$ ICMR Advanced Center for Reverse Pharmacology in Traditional Medicine, \\ Kasturba Health Society, 17 Khandubhai Desai Road, Vile Parle (W), Mumbai 400 056, India
}

\begin{abstract}
Problem statement: The formation of a urinary stone, known as nephrolithiasis, urolithiasis, renal calculi or kidney stone is a serious, debilitating problem in all societies throughout the world. Struvite or Ammonium Magnesium Phosphate Hexahydrate (AMPH) is one of the components of urinary stone (calculi). Struvite stones are commonly found in women. Struvites form in humans as a result of urinary tract infection with ureolithic urea splitting micro organisms. These stones can grow rapidly forming "staghorn-calculi", which is more painful urological disorder. Therefore, it is of prime importance to study the growth and inhibition of Struvite crystals. Approach: This in vitro study had been carried out in the presence of herbal extract of Boerhaavia diffusa Linn. by using single diffusion gel growth technique. Sodium metasilicate solution of specific gravity 1.05 and an aqueous solution of ammonium dihydrogen phosphate of $0.5 \mathrm{M}$ concentration were mixed so that the $\mathrm{pH}$ value 7.0 could be set. After the gelation, equal amount of supernatant solution of $1.0 \mathrm{M}$ magnesium acetate prepared with 0.5 and $1 \%$ concentrations of the herbal extract of $B$. diffusa Linn. were gently poured on the set gels in the respective test tubes in the aseptic medium. Results: The growth of crystals without and with herbal extracts was monitored at regular time intervals. As the concentration of $B$. diffusa Linn. increased, the inhibition of crystals also increased in the gel media as well as the dissolution of crystals at the gel-liquid interface increases. The de-fragmentation of some grown crystals was also noticed. Conclusion: The herbal extract of $B$. diffusa Linn. inhibited the growth of struvite crystals in vitro. This study incorporated multidisciplinary interests and may be used for formulating the strategy for prevention or dissolution of urinary stones.
\end{abstract}

Key Words: Ammonium Magnesium Phosphate Hexahydrate (AMPH), urinary stone, gel growth

\section{INTRODUCTION}

Urinary stone is one of the oldest and common afflictions of humans. A large number of people are suffering from urinary stone problem all over the glob. Not only the humans but animals and birds also suffer from the urinary stone problem. The occurrence in some areas is so alarming that they are known as 'Stone Belts ${ }^{[1]}$. In USA urinary stones are responsible for about 1.3 million medical consults each year with treatment costing about $\$ 2$ billion annually in medical bills ${ }^{[2]}$. As per one estimate 6 lacs Americans suffer from urinary stone problem every year. Whereas, in India $11 \%$ people are expected to be having urinary stone problem and out of them $50 \%$ may lead to loss of kidneys or renal damages. Also, nearly $15 \%$ population of the northern India is suffering from kidney stone problem ${ }^{[3]}$.
The stones are usually formed by one of four substances calcium, uric acid, magnesium ammonium phosphates, or cystine ${ }^{[4]}$. Kidney stones result from the growth of crystals into stones ${ }^{[5]}$. Struvite, Ammonium Magnesium Phosphate Hexahydrate \{(AMPH)$\left.\left(\mathrm{NH}_{4}\right) \mathrm{MgPO}_{4} \cdot 6\left(\mathrm{H}_{2} \mathrm{O}\right)\right\}$, is a biomineral and occurs as crystallites in urine and as a type of kidney stone. It is also known as triple phosphate stone, infection stone or urase stone. Worldwide, they compose $30 \%$ of all kidney stones ${ }^{[6]}$.

Struvites form in humans as a result of urinary tract infection with ureolithic micro organisms that split urea and cause persistently alkaline urine ${ }^{[7-9]}$. The stone formation requires supersaturated urine. Supersaturation also depends on urinary $\mathrm{pH}$, ionic strength, solute concentration and complexations ${ }^{[1]}$. For the formation of Struvite calculi, three conditions must

Corresponding Author: C.K. Chauhan, H and HB Kotak Institute of Science, Dr Yagnik Road, Rajkot-360 001, Gujarat, India 
coexist. (i) Alkaline urine (ii) The presence of urea or ammonia in the urine and (iii) Higher concentration of minerals in the urine. As it is known, Struvite forms as a consequence of a urinary tract infection by urease producing micro organisms, this urease splits urea and produces ammonia. Further hydrolysis of the ammonia takes place, which produces $\mathrm{NH}^{4+}$ ions and increases urine $\mathrm{pH}$ and gives neutral or alkaline urine. An elevated urinary $\mathrm{pH}$ reduces the solubility of magnesium ammonium phosphate and favors precipitation of Struvite crystals. Higher intake of phosphate (from Proteins) and magnesium based food and lower intake of water gives rise to the $\mathrm{PO}_{4}{ }^{3-}$ and $\mathrm{Mg}^{2+}$ ions in the supersaturated urine, which leads to the conditions of formation of Struvite ${ }^{[10]}$.

Urine of a healthy person is under-saturated with regard to Struvite, but because of the conditions provoked by urease-producing microorganisms and the urine complex composition, the precipitation of Struvite can occur. Under such conditions Struvite often precipitates together with apatites and the sediment can easily be attached to the particles of organic matter formed as a consequence of the infection. This mechanism favors the crystal deposition and aggregation, so that Struvite stones grow rather quickly. Struvite stones may grow rapidly over a period of weeks to months and, if not adequately treated, can develop into a Staghorn or branched calculus that involves the entire renal pelvis and calyces. Patients with infected Staghorn calculi who receive no treatment have about a $50 \%$ chance of losing the kidney ${ }^{[1-12]}$. Therefore, it is very much necessary to study the growth-inhibition of Struvite crystals.

In the present investigation, Struvite crystals were grown by single diffusion gel growth technique and the study of the growth inhibition effect on the Struvite crystals in the presence of the different concentration of the herbal extract of one of the medicinal plants, Boerhaavia diffusa Linn. was carried out.

\section{MATERIALS AND METHOD}

Single diffusion gel growth technique: The growth of Struvite can be simulated in the laboratory by growing crystals in silica hydro gel medium. In the gel growth technique, the gel acts as a 'three dimensional crucible' which supports the crystals; at the same time yields to its growth without exerting major forces upon it. This relative freedom from constraint is believed to be an important factor in the achievement of high structural perfection. In the gel growth technique growth occurs due to reaction between two solutions in a gel medium or achieving super-saturation by diffusion in gel medium. Slow and controlled diffusion of reactants in gels can mimic the condition in body. Biocrystallization or bio-mineralization usually occurs in the slow and steady process in the soft tissues. Single diffusion gel growth technique provides the simplified in vitro model of the highly complex growth of urinary calculi in vivo. Growth of crystals with different morphologies is commonly found in bio-mineralization. In the gel growth technique, by changing the growth conditions, crystals with different morphologies and sizes can be obtained. The main advantage is that the crystals can be observed practically in all stages of their growth. The gel growth technique was described in details by Henisch ${ }^{[13]}$, Henisch et al. $^{[14]}$ as well as Patel and $\operatorname{Rao}^{[15]}$.

Urinary stones grow in a gel like medium; therefore, they have radially striated growth ${ }^{[16]}$. The crystal growth by gel method provides simulation of synovial cartilage and other biological fluids ${ }^{[17]}$. Gel growth (in vitro) of a few urinary stone constituents and the inhibitory role played by some extracts or juices of natural products in crystal growth were studied earlier ${ }^{[18]}$. This technique has been successfully used to study the growth inhibition of calcium oxalate crystals $^{[19]}$ and calcium hydrogen phosphate dihydrate crystals $^{[20]}$ using herbal extracts of Tribulus terrestris Linn. and Bergenia Ligulata Linn. Growth inhibition study of Struvite in the presence of the juice of Citrus medica Linn. ${ }^{[21]}$ and in the presence of the herbal extracts of Commiphora wightii ${ }^{[10]}$ and Rotula aquatica Lour. ${ }^{[22]}$ was successfully carried out by the present researchers. Recently, a modified gel growth technique has been proposed for the micro-crystal growth and in situ observations, which has been successfully tested for calcium hydrogen phosphate dihydrate micro crystal growth inhibition in the presence of citric acid ${ }^{[23]}$.

Herbal extract of Boerhaavia diffusa Linn.: In the indigenous Indian system of medicine i.e., in the Ayurveda, many herbal medicines have been recommended for the treatment of urinary stone problem and some of them have been experimentally evaluate $^{[18-22,24-25]}$. In the present growth inhibition study researcher used one of the herbal extractsBoerhaavia diffusa Linn., commonly known as Punarnava, Raktakanda, Varshabhu or Shothaghni in Sanskrit, Spreading Hogweed in English. Boerhaavia diffusa Linn. is a herbaceous plant of the family Nyctaginaceae. It is a small perennial creeping herb distributed widely all over in India and in many other countries. The root and the whole plant is known 
to have medicinal properties and are used as an Ayurvedic medicine in India for the treatment of diabetes, stress, dyspepsia, abdominal pain, inflammation, jaundice, enlargement of spleen, congestive heart failure and bacterial infections ${ }^{[26-31]}$. The plant is known to possess anti-inflammatory ${ }^{[32-33]}$, anticonvulsant ${ }^{[34-35]}$, antifibrinolytic ${ }^{[36]}$, diuretic ${ }^{[37-38]}$, hepatoprotective ${ }^{[39-42]}$ and immunomodulatory ${ }^{\text {[43-44] }}$ activities. It has also been reported to be useful in the treatment of elephantiasis, night blindness, corneal ulcers and nephritic syndrome ${ }^{[45-48]}$.

Experimental technique: The single diffusion gel growth technique was used to study the growth and inhibition behavior of Struvite crystals in the presence of different concentration of the herbal extract Boerhaavia diffusa Linn. The extract of Boerhaavia diffusa Linn. has been prepared by the standard method which is elaborately discussed elsewhere ${ }^{[49]}$. Sodium Metasilicate (SMS)- $\left\{\mathrm{Na}_{2} \mathrm{Si} \mathrm{O}_{3}\right.$, $\left.9 \mathrm{H}_{2} \mathrm{O}\right\}$ solution of specific gravity 1.05 was used to prepare the gel. An aqueous solution of Ammonium Dihydrogen Phosphate (ADP)- $\left\{\mathrm{NH}_{4} \mathrm{H}_{2} \mathrm{PO}_{4}, 2 \mathrm{H}_{2} \mathrm{O}\right\}$ of $0.5 \mathrm{M}$ concentration was mixed with the SMS solution in appropriate amount so that the $\mathrm{pH}$ value 7.0 could be set for the mixture. The gel solution of $20 \mathrm{~mL}$ was transferred into the test tubes of $140 \mathrm{~mm}$ length and $25 \mathrm{~mm}$ diameter. All test tubes and other glassware were autoclaved at $120^{\circ} \mathrm{C}$ for $15 \mathrm{~min}$. Here, the silica gel was chosen so that it remains stable and does not react with the reacting solutions or with the product crystal formed. After the gelation took place, $20 \mathrm{~mL}$ supernatant solutions of pure 1.0 $\mathrm{M}$ magnesium acetate$\left\{\mathrm{C}_{4} \mathrm{H}_{6} \mathrm{Mg} \mathrm{O}_{4}, 4 \mathrm{H}_{2} \mathrm{O}\right\}$ (without inhibitor) and $1.0 \mathrm{M}$ magnesium acetate prepared with 0.5 and $1 \%$ concentrations of the herbal extract Boerhaavia diffusa Linn. were gently poured on the set gels in test tubes to study the growth inhibition of Struvite crystals. This was done in the aseptic medium in laminar flow hood to avoid microbial contaminations. Composition and the $\mathrm{pH}$ value of the supernatant solution are as shown in Table 1. After pouring supernatant solution, the test tubes were capped with airtight stopples. The experiment was conducted at the room temperature.

Table 1: Composition of supernatant solution

\begin{tabular}{lllll}
\hline & \multicolumn{5}{c}{ Composition } \\
& & ----------------------------- \\
& Distilled & Magnesium & B. diffusa \\
Concentration & Water (mL) & acetate (g) & Linn. (g) \\
\hline No Inhibitor & 8.00 & 20 & 4.288 & - \\
0.5\% B. diffusa Linn. & 7.25 & 20 & 4.288 & 0.100 \\
$1 \%$ B. diffusa Linn. & 7.00 & 20 & 4.288 & 0.200 \\
\hline
\end{tabular}

The following reaction is expected to occur in the gel between the two reactants:

$$
\begin{aligned}
& \mathrm{NH}_{4} \mathrm{H}_{2} \mathrm{PO}_{4} \cdot 2 \mathrm{H}_{2} \mathrm{O}+\left(\mathrm{CH}_{3} \mathrm{COO}\right)_{2} \mathrm{Mg} \cdot 4 \mathrm{H}_{2} \mathrm{O} \\
& \rightarrow \mathrm{NH}_{4} \mathrm{MgPO}_{4} \cdot 6 \mathrm{H}_{2} \mathrm{O}+2 \mathrm{CH}_{3} \mathrm{COOH}
\end{aligned}
$$

The apparent lengths of growing/dissolving Struvite crystals in each of the test tubes were measured by using a traveling microscope of least count $0.001 \mathrm{~cm}$ at regular time interval. The apparent lengths of growing/dissolving Struvite crystals at the different depth from gel-liquid interface in each of the test tubes were measured and mean length of the crystals at the different depth was calculated. The statistical analysis of the single factor ANOVA was carried out. At the end of the experiment, Struvite crystals were gently removed from the gel medium of each of the test tubes. Average of the total mass and the total volume of the grown Struvite crystals in each of the concentration were found out.

\section{RESULTS AND DISCUSSION}

There are substances, which change or modify crystal formation, which can be divided into three groups as inhibitors, complexors and promoters. Urinary inhibitors attach to the growth sites on crystalline face and retard the growth and aggregation further. Recently, the growth inhibition of hydroxyapatite crystals is studied at physiological temperature in vitro by using-Boswellia serrata Roxb., Tribulus terrestris Linn., Rotula aquatica Lour., Boerhaavia diffusa Linn. and Commiphora wightii herbal extract solutions and the diffusion constants were measured for $\mathrm{Ca}^{++}$ions ${ }^{[50]}$. For Struvite crystals not significant amount of growth inhibition is reported. The present authors have recently identified the inhibition produced by the herbal extract Commiphora wightti ${ }^{[10]}$, Rotula aquatica Lour. ${ }^{[22]}$ and the juice of Citrus medica Linn. ${ }^{[21]}$. In the present investigation herbal extract of Boerhaavia diffusa Linn. is used to study the growth inhibition of Struvite crystals in vitro in growth conditions.

Struvite crystals with different morphologies like dendritic type, prismatic type, rectangular platelet type, needle type were grown in the gel ${ }^{[51]}$. Figure 1 shows the photographs of the grown Struvite crystals in the gel medium. It was seen that as the concentration of the herbal extract Boerhaavia diffusa Linn. was increased in the supernatant solution, the number of grown Struvite crystals in the silica hydro gel medium decreased and also average size of the Struvite crystals decreased as shown in Fig. 2. The average size of the prismatic type crystals grown is $0.7 \mathrm{~cm}$ in the case of no inhibitor, 
Am. J. Infect. Dis., 5 (3): 170-179, 2009

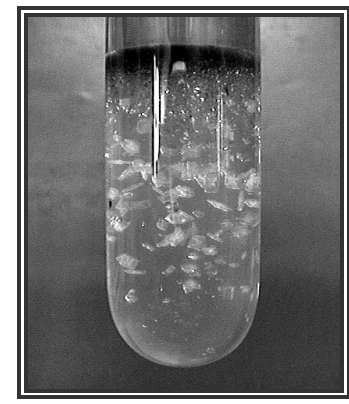

(a)

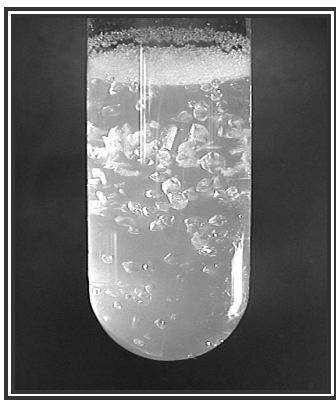

(b)

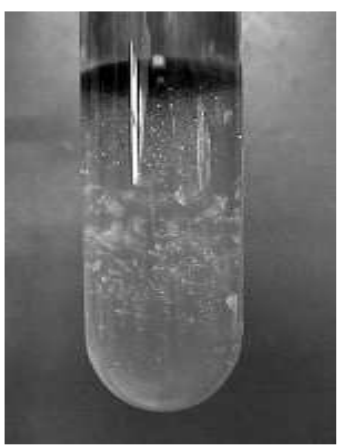

(c)

Fig. 1: Struvite crystals grown in Gel medium. (a): No. Inhibitor; (b): $0.5 \%$ B. diffusa Linn.; (c) $1 \%$ B. diffusa Linn.

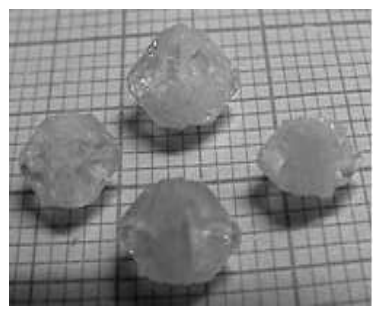

(a)

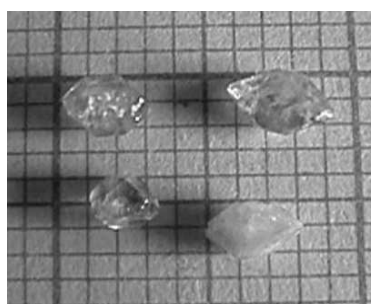

(b)

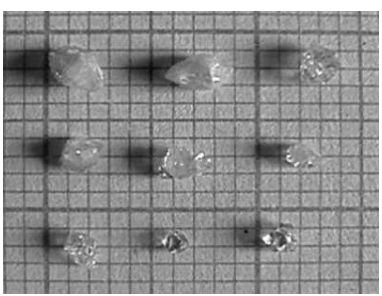

(c)

Fig. 2: Variation in the size of the Struvite crystals in different concentration. (a): No. Inhibitor; (b): $0.5 \%$ B. diffusa Linn.; (c): $1 \%$ B. diffusa Linn.

whereas it was $0.35 \mathrm{~cm}$ in the case of $0.5 \%$ B. diffusa Linn. and was $0.2 \mathrm{~cm}$ in the case of $1 \%$ B. diffusa Linn.
Table 2: Growth/Dissolution rate of Struvite crystals in gel at gelliquid interface

\begin{tabular}{|c|c|c|c|c|}
\hline \multirow[b]{2}{*}{$\begin{array}{l}\text { Growth/dissolution } \\
\text { rate }\end{array}$} & \multirow[b]{2}{*}{ Day } & \multicolumn{3}{|c|}{ Concentration } \\
\hline & & $\begin{array}{l}\text { No. } \\
\text { inhibitor }\end{array}$ & $\begin{array}{l}0.5 \% \\
\text { B. diffusa } \\
\text { Linn. }\end{array}$ & $\begin{array}{l}1 \% \\
\text { B. diffusa } \\
\text { Linn. }\end{array}$ \\
\hline Growth rate & 1 & 1.185 & 1.027 & 0.825 \\
\hline \multirow[t]{3}{*}{$\left(\mathrm{cm}\right.$ days $\left.^{-1}\right)$} & 2 & 0.608 & 0.534 & 0.413 \\
\hline & 3 & 0.410 & $\begin{array}{l}\text { Dissolution } \\
\text { starts }\end{array}$ & $\begin{array}{l}\text { Dissolution } \\
\text { starts }\end{array}$ \\
\hline & 4 & 0.309 & - & - \\
\hline $\begin{array}{l}\text { Dissolution rate } \\
\left(\mathrm{cm} \mathrm{days}^{-1}\right)\end{array}$ & & $1.8 \times 10^{-2}$ & $3.4 \times 10^{-2}$ & $4.3 \times 10^{-2}$ \\
\hline
\end{tabular}

After the pouring of supernatant solution, dendritic type crystals were found to grow at the gel-liquid interface. The growth rates of Struvite crystals, at the end of 1st, 2nd, 3rd and 4th day, growing in the gel at gel-liquid interface for the different concentration of supernatant solution were as shown in Table 2. It can be noticed from the growth rate observations that the growth rate of the growing Struvite crystals and hence the size of the crystals decreases as the concentration of the $B$. diffusa Linn. increases. It was observed that the length of the Struvite crystals growing in the gel at gelliquid interface increases up to first 4 days in the normal case i.e., without any inhibitor, where as it increases up to first 2 days and than it started dissolving in the case of 0.5 and $1 \%$ concentrations of $B$. diffusa Linn. From the Table 2 it can be noticed that the growth rate decreases with the increasing concentration of $B$. diffusa Linn. The maximum apparent length of the grown Struvite crystals at the gel-liquid interface is $1.235 \mathrm{~cm}$ in the case of no inhibitor, whereas it is $1.067 \mathrm{~cm}$ and $0.865 \mathrm{~cm}$ for 0.5 and $1 \% B$. diffusa Linn., respectively; which shows that as the concentration of $B$. diffusa Linn. increases in the supernatant solution, maximum apparent length of the grown crystals in the silica hydro gel medium decreases.

The maximum depth of growth, i.e. the depth from the gel-liquid interface in gel up to which Struvite crystals are grown, $5.2 \mathrm{~cm}$ was observed after 2 days in case of no inhibitor (or control solution), while it was $2.9 \mathrm{~cm}$ and $2.6 \mathrm{~cm}$ after 2 days for 0.5 and $1 \%$ concentrations of $B$. diffusa Linn., respectively. This suggests that the herbal extract impedes the diffusion process of reactants occurring in the gel column for the nucleation and subsequently the growth of crystals. The concentration gradient is the maximum at the gel-liquid interface, which decreases gradually on moving towards the bottom of the test tubes. Thus the reduction in the value of the depth of growth indicates the inhibition offered by the herbal extracts. 


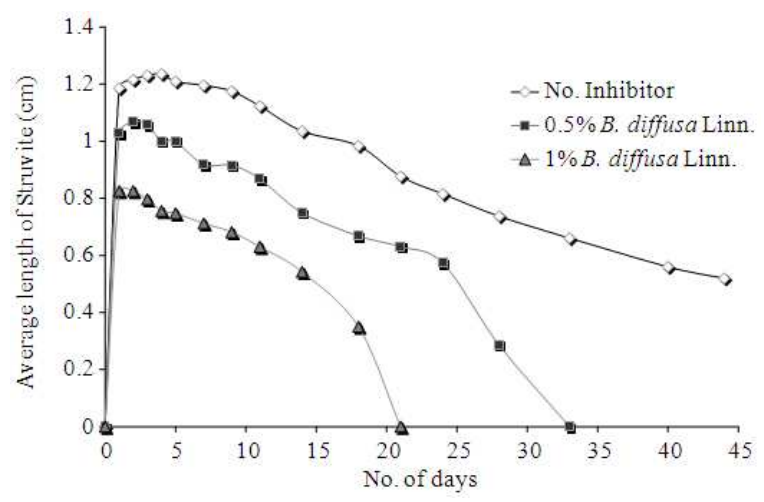

Fig. 3: Growth and dissolution of Struvite at gel-liquid interface

Due to high concentration of reactants at the gelliquid interface, more-or-less, a direct reaction is taking place, which results in to dendritic type crystals. It was observed that dendritic type Struvite crystals, grown in the gel at the gel-liquid interface dissolved completely within 33 days in case of $0.5 \%$ concentration of $B$. diffusa Linn. whereas within 21 days in the case of $1 \%$ concentration of B. diffusa Linn. The growth and dissolution of Struvite crystals at the gelliquid interface is shown by plots of average length versus time period in Fig. 3. Here it was found that Struvite crystals dissolved at some extent grown at the gel-liquid interface even in the absence of inhibitor. It may be due to dissolution in acetic acid which is formed due to the chemical reaction as shown in Eq. 1. But it is observed that the dissolution becomes faster for different concentrations of B. diffusa Linn. From the ANOVA single factor analysis it was found that the differences in the average lengths in each of the case were highly significant at 0.05 level. The dissolution rate of Struvite crystals grown in the gel at gel-liquid interface for the different concentration of $B$. diffusa Linn. is as shown in Table 2. It can be seen that the dissolution rate increases with the increasing concentration of $B$. diffusa Linn.

Inasmuch as the growth of calculi continuously occurs by the supply of nutrients through urine, the in vitro growth inhibition or dissolution study is important. In the gel growth the nutrients are constantly being supplied to the growing crystals and the dissolution or inhibition is to be checked for the selected solution. It is not a simple dissolution of crystal, which can simply be achieved by placing a selected crystal in herbal extract solution and measure the dissolution. In the absence of the inhibitor, the dissolution of the crystals took place only at the gelliquid interface; this is due to high concentration gradient of acetic acid at the gel-liquid interface.

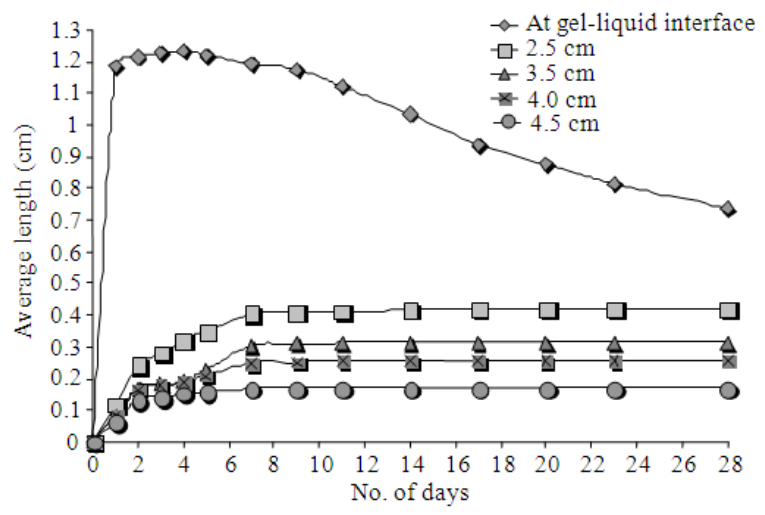

Fig. 4: Growth and dissolution of Struvite at different depth from the gel-liquid interface in the absence of inhibitor

Table 3: Enhanced dissolution rate of Struvite crystals in gel at gelliquid interface in the presence of B. diffusa Linn.

\begin{tabular}{lccc}
\hline & $\begin{array}{l}\text { Dissolution } \\
\text { rate } \\
\left(\mathrm{cm} \mathrm{days}^{-1}\right)\end{array}$ & $\begin{array}{l}\text { Enhanced } \\
\text { dissolution } \\
\text { rate }\left(\mathrm{cm} \mathrm{days}^{-1}\right)\end{array}$ & $\begin{array}{l}\text { Percentage of } \\
\text { enhanced } \\
\text { dissolution rate }\end{array}$ \\
\hline Noncentration & $1.8 \times 10^{-2}$ & - & - \\
$0.5 \%$ B. diffusa Linn. & $3.4 \times 10^{-2}$ & $1.6 \times 10^{-2}$ & 88.89 \\
$1 \%$ B. diffusa Linn. & $4.3 \times 10^{-2}$ & $2.5 \times 10^{-2}$ & 138.89 \\
\hline
\end{tabular}

But the dissolution of the crystals did not take place on going towards the bottom of the test tube because the concentration gradient of acetic acid decreased. In the cases of 0.5 and $1 \%$ concentrations of $B$. diffusa Linn., however, the enhanced dissolution of the crystals was observed at the gel-liquid interface; which was partially due to the formation of acetic acid and partially due to the presence of $B$. diffusa Linn. This enhanced dissolution rate due to $B$. diffusa Linn. is confirmed by the comparative values of crystal dissolution rates given in a separate Table 3. The percentage of enhanced dissolution rate of Struvite crystals grown in the gel at the gel-liquid interface is 88.89 and $138.89 \%$ for 0.5 and $1 \%$ concentrations of $B$. diffusa Linn., respectively.

Growth and dissolution of grown Struvite crystals at different depth in gel from the gel-liquid interface in the absence inhibitor is shown by plots of average apparent length versus time period in Fig. 4. It is observed that the length of growing crystals in the gel at gel-liquid interface increased up to first 4 days and then started dissolving, due to the formation of acetic acid. It is also noticed that the length of the crystals at different depth from the gel-liquid interface increased up to first 7 days and then it remained constant up to about 45 days. As the depth of the gel column increases from the gelliquid interface, the average apparent lengths of the grown crystals were found to be gradually smaller. 
Am. J. Infect. Dis., 5 (3): 170-179, 2009

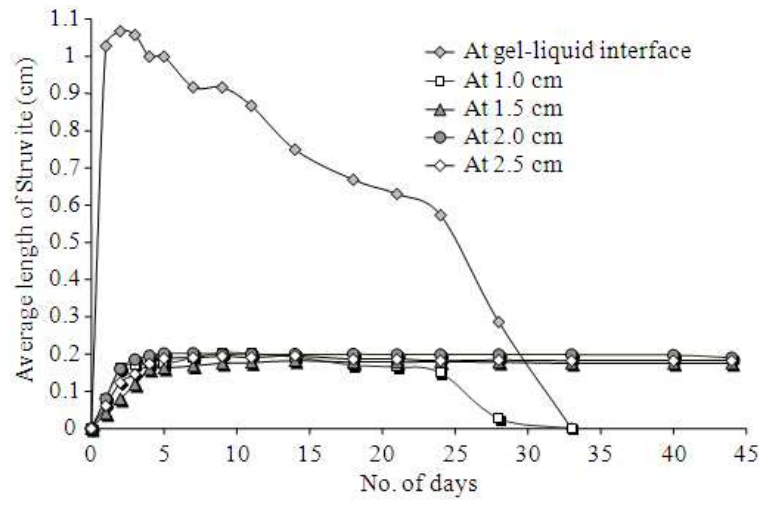

Fig. 5: Growth and dissolution of Struvite at different depth from the gel-liquid Interface for the $0.5 \%$ B. diffusa Linn.

Table 4: Inhibition of Struvite crystal growth in gel at gel-liquid interface in the presence of $B$. diffusa Linn. on 1st day

\begin{tabular}{|c|c|c|c|}
\hline Concentration & $\begin{array}{l}\text { Average } \\
\text { apparent } \\
\text { crystal } \\
\text { length }(\mathrm{cm})\end{array}$ & $\begin{array}{l}\text { Reduction } \\
\text { in crystal } \\
\text { length } \\
(\mathrm{cm})\end{array}$ & $\begin{array}{l}\text { Percentage of } \\
\text { the inhibition } \\
\text { of Struvite } \\
\text { crystal growth }\end{array}$ \\
\hline No Inhibitor & 1.185 & - & - \\
\hline 0.5\% B. diffusa Linn. & 1.027 & 0.158 & 13.33 \\
\hline $1 \%$ B. diffusa Linn. & 0.825 & 0.360 & 30.37 \\
\hline
\end{tabular}

Growth and dissolution of the grown Struvite crystals at different depths in the gel from the gel-liquid interface in the case of 0.5 and $1 \%$ concentrations of $B$. diffusa Linn. are as shown in the plots of average length versus time period in Fig. 5 and 6, respectively. The similar phenomena were observed more effectively in the presence of inhibitor $B$. diffusa Linn. It was observed that the length of growing crystals in the gel at gel-liquid interface increased up to first 2 days in both the cases of 0.5 and $1 \%$ concentration of $B$. diffusa Linn. It was noticed that in these cases, the growth rate as well as the size of the crystals grown were lower. The inhibition of crystal growing in the gel at the gelliquid interface in the presence of $B$. diffusa Linn., at the end of very 1st day after the pouring of supernatant solution is shown in Table 4. The percentages of the inhibition of Struvite crystal growing in the gel at the gel-liquid interface at the end of very 1 st day are 13.33 and $30.37 \%$ in the case of 0.5 and $1 \%$ concentrations of $B$. diffusa Linn., respectively, which indicates the inhibitive effect of $B$. diffusa Linn. It was found that as the depth increased, the size of the grown crystals decreased. The concentration gradient decreases in the gel column as the depth increases, therefore, the concentration of $B$. diffusa Linn. also decreases. The lower concentration of the $B$. diffusa Linn. still produces the inhibition, which can be confirmed by comparing the relative size of crystals in pure control solution and the $B$. diffusa Linn. containing solutions.

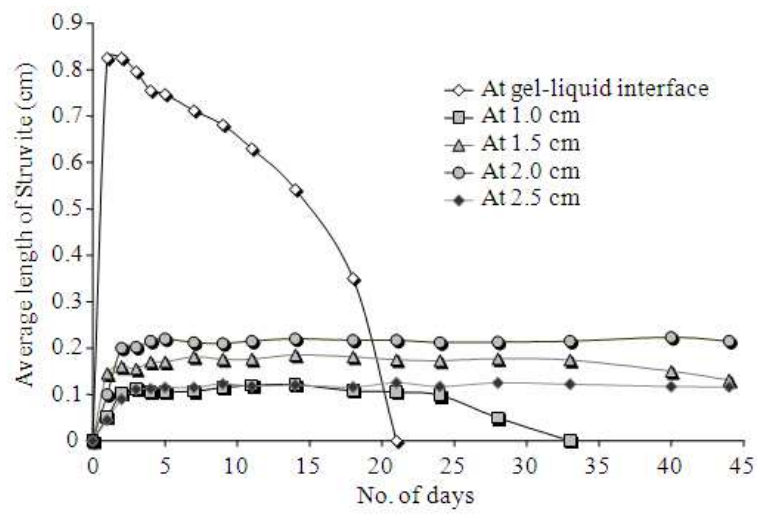

Fig. 6: Growth and dissolution of Struvite at Different depth from the gel-liquid interface for the $1 \%$ B. diffusa Linn.

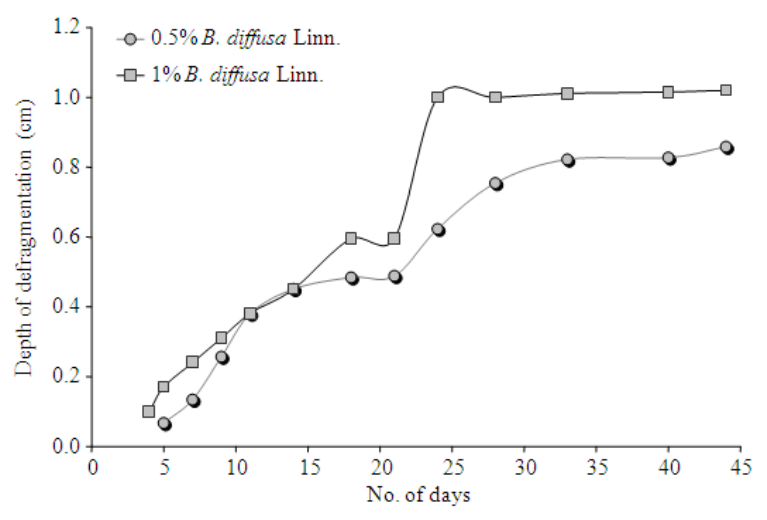

Fig. 7: Depth of fragmentation versus days

It was found that as the depth increased, the size of the grown Struvite crystals decreased. The maximum length of the crystals grown at the depth of $2.5 \mathrm{~cm}$ is $0.418 \mathrm{~cm}$ in the case of no inhibitor, whereas it was $0.195 \mathrm{~cm}$ in the case of $0.5 \%$ concentration of $B$. diffusa Linn. and was $0.125 \mathrm{~cm}$ in the case of $1 \%$ concentration of $B$. diffusa Linn., which shows that as the concentration of $B$. diffusa Linn. increases in the supernatant solution, maximum apparent length of the grown crystals in the silica hydro gel medium decreases. It is noticed that the maximum length of the grown crystals at the depth of $2.5 \mathrm{~cm}$ decreases on increasing the concentration of $B$. diffusa Linn.

The fragmentation of the crystals grown near the gel-liquid interface was also noticed in the cases of 0.5 and $1 \%$ concentrations of $B$. diffusa Linn. Figure 7 shows the depth of fragmentation i.e., the depth from the gel-liquid interface up to which crystals started to break into several tiny crystals. The size of the crystals after fragmentation was found even less than $1 \mathrm{~mm}$. 


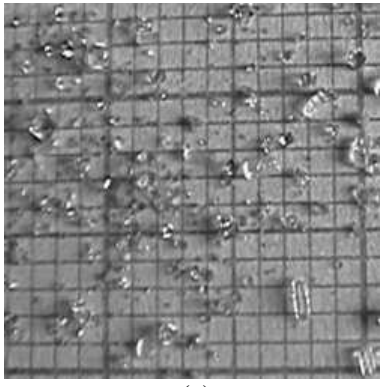

(a)

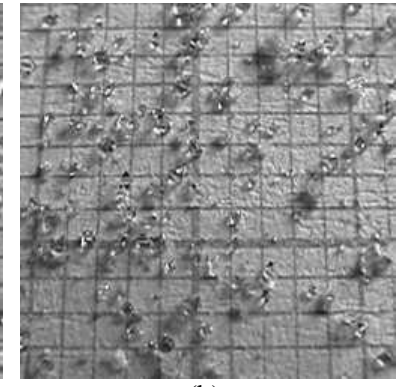

(b)
Fig. 8: Size of the Struvite crystals after fragmentation. (a): $0.5 \%$ B. diffusa Linn.; (b): $1 \%$ B. diffusa Linn.

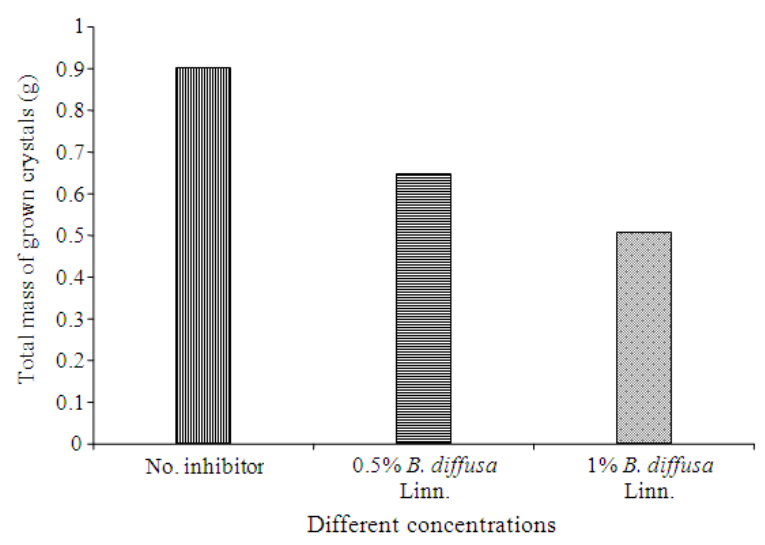

Fig. 9: Total mass of the grown Struvite crystals in different concentration

Figure 8 shows the photograph of the Struvite crystals after fragmentation. After the fragmentation, the dimensions are far less than $5 \mathrm{~mm}$, that is the maximum dimension of the urinary crystal or calculi which can easily pass through the urinary tract.

After the growth and dissolution studies, the Struvite crystals were gently removed from the gel and the total mass as well as the total volume of the crystals for each concentration was measured. Figure 9 and 10 show the histograms depicting the total mass and total volume of the grown crystals for each concentration. It was noted that both the total mass and the total volume of the grown crystals decreased with the increasing concentration of $B$. diffusa Linn. It can be concluded that $B$. diffusa Linn. is found to be a potent inhibitor for Struvite crystal growth in vitro. This in vitro study may be helpful to identify the potent inhibitors for in vivo studies.

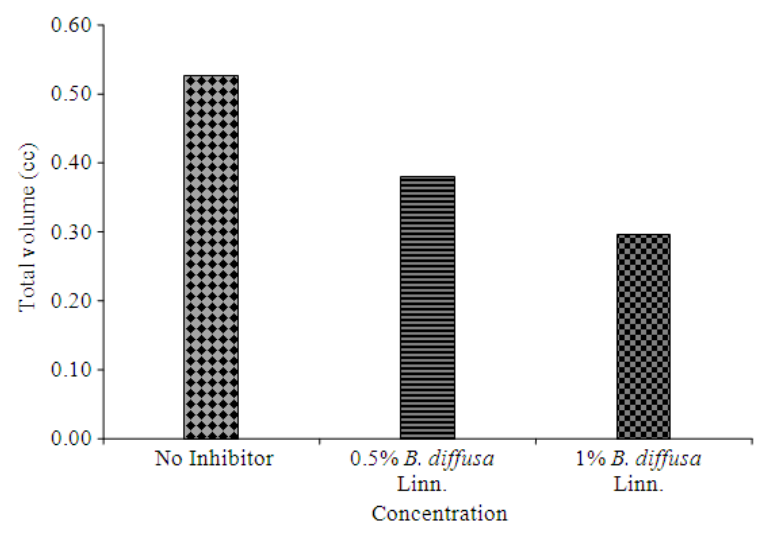

Fig. 10: Total volume of the grown Struvite crystals in different concentration

\section{CONCLUSION}

As the concentration of the herbal extract Boerhaavia diffusa Linn. was increased in the supernatant solution, the number of grown Struvite crystals in the silica hydro gel medium was decreased. The dimension of the Struvite crystals was reduced due to inhibition produced by $B$. diffusa Linn. The average size of the prismatic type crystals was $0.35 \mathrm{~cm}$ in the case of $0.5 \%$ B. diffusa Linn. and was just $0.2 \mathrm{~cm}$ in the case of $1 \% B$. diffusa Linn. From the ANOVA single factor analysis it was found that the differences in the average lengths in each of the case were highly significant at 0.05 level. Growth rate of the growing Struvite crystals was decreased as the concentration of the $B$. diffusa Linn. increased. The depth of growth was also found less for the higher concentration of the $B$. diffusa Linn. It was noticed that the dissolution rate increases with the increasing concentration of $B$. diffusa Linn. The fragmentation of the crystals grown near the gel-liquid interface was also noticed when $B$. diffusa Linn. was used as inhibitor. The size of the crystals after fragmentation was found even less than $1 \mathrm{~mm}$, which was far less than $5 \mathrm{~mm}$, that is the maximum dimension of the urinary crystal or calculi which can easily pass through the urinary tract. It was also found that both the total mass and the total volume of the grown Struvite crystals decreased with the increasing concentration of $B$. diffusa Linn. Although the stone formation process occurring in the human body is quite complex and takes place in a dynamic environment, from the present study we can say that the herbal extract of $B$. diffusa Linn. inhibits the growth of Struvite crystals in vitro. This study may be used for formulating the strategy for prevention or cure. 


\section{ACKNOWLEDGEMENT}

The researchers are thankful to the UGC, New Delhi, for the financial assistance under SAP and Profs. K.N. Iyer and H.H. Joshi, Physics Department, Saurashtra University, Rajkot, for their keen interest. The authors are thankful to Dr Ashwinikumar Raut and Dr Nancy Pandita for providing herbal extracts. The researcher (CKC) is thankful to the Dept. of Education, Govt. of Gujarat; Smt. Jayanti S. Ravi, Commissioner of Higher Education and Joint Director, CHE, Gandhinagar; Mr. N.T. Chotaliya, Principal, H. and H.B. Kotak Institute of Science, Rajkot, for their encouragements.

\section{REFERENCES}

1. Menon, M., B.G. Parulkar and G.W. Drach, 1998. Urinary Lithiasis, Etiology, Diagnosis, and Medical Management. In: Campbell's Urology, Vol 3, Walsh, P.C. (Ed.). 7th Edn., WB Saunders Co., Philadelphia, ISBN: 0721644643, pp. 2661-2733.

2. Bethesda, Md., 2001. Kidney and urologic diseases statistics for the United States. National Institute of Diabetes and Kidney Diseases.

http://www.niddk.nih.gov/health/kidney/pubs/kusta ts/kustats.htm

3. Tribune News Service, 2000. Leafy vegetables cause stones.

http://www.tribuneindia.com/2000/20001102/cth3. htm

4. Pak, C.Y.C., 1998. Kidney stones. Lancet, 351: 1797-1801. DOI : $10.1016 /$ S01406736(98)01295-1

5. Kok, D.J., 2002. Clinical implications of physicochemistry of stone formation. Endocrinol. Metab. Clin. North Am., 31: 855-867. http://linkinghub.elsevier.com/retrieve/pii/S088985 2902000373

6. Maxwell Meng, M. and L. Stoller, 2005. Struvite and Staghorn Calculi-Website of E-Medicine by WebMD. http://www.e-medicine.com/MED/topic2834.htm

7. Griffith, D.P., 1978. Struvite stones. Kidney Int., 13: 372-382. DOI: 10.1038/ki.1978.55

8. Coe, F.L., J.H. Parks and J.R. Asplin, 1992. The pathogenesis and treatment of kidney stones. N. Engl. J. Med., 327: 1141-1152. PMID: 1528210

9. Hesse, A. and D. Heimbach, 1999. Causes of phosphate stone formation and the importance of metaphylaxis by urinary acidification: A review. World J. Urol., 17: 308 . DOI: $10.1007 / \mathrm{s} 003450050152$
10. Chauhan, C.K., M.J. Joshi and A.D.B. Vaidya, 2008. Growth inhibition of struvite crystals in the presence of herbal extract Commiphora wightii. J. Mater Sci. Mater Med., DOI: 10.1007/s10856-0083489-z

11. Wojewski, A. and T. Zajaczkowski, 1974. The treatment of bilateral Staghorn calculi of the kidneys. Int. Urol. Nephrol., 5: 249-260 PMID: 4829131

12. Singh, M., R. Chapman, G.C. Tresidder and Y.J. Bland, 1973. The fate of the unoperated staghorn calculous. Br. J. Urol., 45: 581-585 DOI: 10.1111/j.1464-410X.1973.tb12226.x

13. Henisch, H.K., 1973. Crystal Growth in Gels. The Pennsylvania State University Press, University Park, ISBN: 0486689158, pp: 41-57.

14. Henisch, H.K., J. Dennis and J.I. Hanoka, 1965. Crystal growth in gels. J. Phys. Chem. Solids, 26: 493-500. DOI: 10.1016/0022-3697(65)90123-X

15. Patel, A.R. and A.V. Rao, 1982. Crystal growth in gel media. Bull. Mater. Sci., 4: 527-548. DOI: 10.1007/BF02824961

16. Iwata, H., Y. Abe, S. Nishio, A. Wakatsuki, K. Ochi and M. Takeuchi, 1986. Crystal-matrix interrelations in brushite and uric acid calculi. J. Urol., 135: 397-401. http://www.ncbi.nlm.nih.gov/pubmed/3944880

17. Achilles, W., R. Freitag, B. Kiss and H. Riedmiller, 1995. Quantification of crystal growth of calcium oxalate in gel and its modification by urinary constituents in a new flow model of crystallization. J. Urol., $\quad 154$ : 1552-1556. http://linkinghub.elsevier.com/retrieve/pii/S002253 4701669271

18. Natarajan, S., E. Ramachandran and D. Blisin Suja, 1997. Growth of some urinary crystals and studies on inhibitors and promoters. II. X-ray studies and inhibitory or promotery role of some substances. Cryst. Res. Technol., 32: 553-559. DOI: 10.1002/crat.2170320409

19. Joshi, V.S., B.B. Parekh, M.J. Joshi and A.D.B. Vaidya, 2005. Herbal extracts of Tribulus terrestris and Bergania ligulata inhibit growth of calcium oxalate monohydrate crystals in vitro. J. Crys. Growth, 275:.1403. DOI: 10.1016/j.jcrysgro.2004.11.240

20. Joshi, V.S., B.B. Parekh, M.J. Joshi and A.D.B. Vaidya, 2005. Inhibition of growth of urinary CHPD crystals with aqueous extracts of Tribulus terrestris and Bergania ligulata. Urol. Res., 33: 80-86. DOI: 10.1007/s00240-004-0450-6

21. Chauhan, C.K. and M.J. Joshi, 2008. Growth inhibition of struvite crystals in the presence of juice of Citrus medica Linn. Urol. Res. DOI: 10.1007/s00240-008-0154-4 
22. Chauhan, C.K., M.J. Joshi and A.D.B. Vaidya, 2008. Growth Inhibition of Struvite crystals in the presence of herbal extract Rotula aquatica Lour. Ind. J. Biochem. Biophys.

23. Parekh, B.B., M.J. Joshi and A.D.B. Vaidya, 2007. Modification of gel technique for micro-crystals of bio-materials: In situ growth and dissolution studies. Curr. Sci., 93: 373-378. http://www.ias.ac.in/currsci/aug102007/373.pdf

24. Joshi, V.S. and M.J. Joshi, 2003. Influence of inhibition citric acid and lemon juice to the growth of calcium hydrogen phosphate dihydrate urinary crystals. Ind. J. Pure Appl. Phys., 41: 183-192. http://cat.inist.fr/?aModele $=$ afficheN\&cpsidt $=14602478$

25. Joseph, K.C., B.B. Parekh and M.J. Joshi, 2005. The inhibition of growth of urinary type CHPD crystals by tartaric acid and tamarind. Curr. Sci., 88: $1232-1238$. http://www.ias.ac.in/currsci/apr252005/1232.pdf

26. Nadkarni, K.M., 1954. Boerhaavia diffusa Linn. Indian Materia Medica, 3rd Edn., Popular Book Depot, Mumbai, ISBN: 8171541429, pp: 202-207.

27. Kirtikar, K.R. and B.D. Basu, 1933. Boerhaavia diffusa Linn. Indian Medicinal Plants. 2nd Edn., Lalit Mohan Basu Publications, Allahabad, India, ISBN: 817089056X, pp: 1052-1054.

28. Chopra, R.W., I.C. Chopra, K.L. Handa and L.D. Kapur, 1958. Medicinal Plants in Diabetes. In: Indiginous Drugs of India, Gupta, P. (Ed.). 2nd Edn., Dhar and Sons Ltd., Calcutta, India, pp: 314-316. http://fore.research.yale.edu/forebib/239.shtml

29. Chopra, R.N., S.L. Nayar and I.C. Chopra, 1956. Glossary of Indian Medicinal Plants. Council of Scientific and Industrial Research (CSIR). New Delhi, India, ISBN: 8172361262, pp: 39.

30. Aslam M., 1996. Asian Medicine and Its Practise in Britain. In: Trease and Evans' Pharmacognosy, William Charles Evans and George Edward Trease (Eds.). Saunders Company Ltd., London, UK., ISBN: 0702018996, pp: 499-500.

31. Olukoya, D.K., N. Tdika and T. Odugbemi, 1993. Antibacterial activity of some medicinal plants from Nigeria. J. Ethnopharmacol., 39: 69-72. http://www.ncbi.nlm.nih.gov/pubmed/8331963

32. Bhalla, T.N., M.B. Gupta and K.P. Bhargava, 1971. Antiinflammatory activity of Boerhaavia diffusa. J. Res. Ind. Med., 6: 11-15.

33. Hiruma-Lima, C.A., J.S. Gracioso, E.J. Bighetti, R.L. Germonsen and B.A.R. Souja, 2000. The juice of fresh leaves of Boerhaavia diffusa L. (Nyctaginaceae) markedly reduces pain in mice. J. Ethnopharmacol., 71: 267-274.

http://www.ncbi.nlm.nih.gov/entrez/query.fcgi?db= PubMed\&cmd=Retrieve\&list_uids=10904173\&Do $\mathrm{pt}=$ Citation
34. Mudgal, V., 1975. Studies on medicinal properties of Convolvulus pluricaulis and Boerhaavia diffusa. Planta Med., 28: 62-68. http://www.ncbi.nlm.nih.gov/entrez/query.fcgi?cm $\mathrm{d}=$ Retrieve $\& \mathrm{db}=$ PubMed\&list_uids=1178789\&dop $\mathrm{t}=$ Citation

35. Adesina, S.K., 1979. Anticonvulsant properties of the roots of Boerhaavia diffusa. Q. J. Crude Drug Res., 17: 84-86.

http://www.informapharmascience.com/doi/ref/10. 3109/13880207909067455

36. Jain, G.K. and N.M. Khanna, 1989. Punarnavoside: A new antifibrolytic agent from Boerhaavia diffusa L. Ind. J. Chem., 28: 163-166. http://indianmedicine.eldoc.ub.rug.nl/root/J2/71j/

37. Singh, R.P., K.P. Shokala, B.L. Pandey, R.G. Singh, Usha and R. Singh, 1992. Recent approach in clinical and experimental evaluation of diuretic action of Purnarnava (Boerhaavia diffusa) with special effect to nephrotic syndrome. J. Ind. Med. Res., 11: 29-36. http://indianmedicine.eldoc.ub.rug.nl/root/S/11650 3/?pFullItemRecord=ON

38. Gaitonde, B.B., H.J. Kulkarni and S.D. Nabar, 1974. Diuretic activity of punarnava (Boerhaavia diffusa). Bull. Haffkine Inst. (Bombay, India), 2: 24-24. http://indianmedicine.eldoc.ub.rug.nl/root/G/30080 $/$ ?pFullItemRecord $=\mathrm{ON}$

39. Chakraborty, K.K. and S.S. Handa, 1989. Antihepatotoxic investigations of Boerhaavia diffusa L. Ind. Drugs, 27: 161-166.

40. Chandan, B.K., A.K. Sharma and K.K. Anand, 1991. Boerhaavia diffusa: A study of its hepatoprotective activity. J. Ethnopharmacol., 31: 299-307.

http://www.ncbi.nlm.nih.gov/entrez/query.fcgi?cmd=Ret rieve $\& d b=$ PubMed\&list_uids $=2056758 \&$ dopt $=$ Citation

41. Rajukumari, G., A. Sarla and S.S. Agarwal, 1991. Hepatoprotective activity of Boerhaavia diffusa Linn. against country made liquor induced hepatotoxicity in albino rats fed on controlled calorie diet. Ind. J. Pharmacol., 23: 264-267. http://ijp-online.com/article.asp?issn=0253-

7613; year $=1991$; volume $=23 ;$ issue $=4 ;$ spage $=264$; ep age $=267$; aulast $=$ Rajkumari; type $=0$

42. Rawat, A.K., S. Mehrotra, S.C. Tripathi and U. Shome, 1997. Hepatoprotective activity of Boerhaavia diffusa L. roots-a popular Indian ethnomedicine. J. Ethnopharmacol., 56: 61-68.

http://www.ncbi.nlm.nih.gov/entrez/query.fcgi?cm $\mathrm{d}=$ Retrieve $\& \mathrm{db}=$ PubMed\&list_uids=9147255\&dop $\mathrm{t}=$ Citation 
43. Mehrotra, S., K.P. Mishra, R. Maurya, R.C. Srimal and V.K. Singh, 2002. Immunomodulation by ethanolic extract of Boerhaavia diffusa roots. Int. Immunopharmacol., 2: 987-996.

http://www.ncbi.nlm.nih.gov/entrez/query.fcgi?cm $\mathrm{d}=$ Retrieve $\& \mathrm{db}=$ pubmed $\&$ list_uids $=12188040 \& \mathrm{do}$ $\mathrm{pt}=$ Citation

44. Mehrotra, S., V.K. Singh, S.S. Agarwal, R. Maurya and R.C. Srimal, 2002. Antilymphoproliferative activity of ethanolic extract of Boerhaavia diffusa roots. Exp. Mol. Pathol., 72: 236-242. http://www.ncbi.nlm.nih.gov/pubmed/12009788

45. Mishra, J. and R. Singh, 1980. The effect of indigenous drug Boerhaavia diffusa on kidney regeneration. Ind. J. Pharmacol., 12: 59-64.

46. Singh, R.H. and K.N. Udupa, 1972. Studies on the Indian indigenous drug Punarnava (Boerhaavia diffusa L.) Part I, Identification and pharmacological studies. J. Res. Ind. Med., 7: 1-12.

47. Singh, R.H. and K.N. Udupa, 1972. Studies on the Indian indigenous drug Punarnava (Boerhaavia diffusa L.) Part III. Experimental and pharmacological studies. J. Res. Ind. Med., 7: 17-27.
48. Singh, R.H. and K.N. Udupa, 1972. Studies on the Indian indigenous drug Punarnava (Boerhaavia diffusa L.) part IV. Preliminary controlled clinical trial in nephrotic syndrome. J. Res. Ind. Med., 7: 28-33. http://indianmedicine.eldoc.ub.rug.nl/root/S/11645 9/?pFullitemRecord=ON

49. Pari, L. and M. Amarnath Satheesh, 2004. Antidiabetic effect of Boerhavia diffusa: Effect on serum and tissue lipids in experimental diabetes. J. Med. Food, 7: 472-476. DOI: 10.1089/jmf.2004.7.472

50. Parekh, B.B., M.J. Joshi and A.D.B. Vaidya, 2008. Characterization and inhibitive study of gel-grown hydroxyapatite crystals at physiological temperature. J. Cryst. Growth, 310: 1749-1753. DOI: $10.1016 /$ j.jcrysgro.2007.11.219

51. Chauhan, C.K., K.C. Joseph, B.B. Parekh and M.J. Joshi, 2008. Growth and characterization of Struvite crystals, Ind. J. Pure Appl. Phys., 46: 507-512. http://www.niscair.res.in/sciencecommunication/R esearchJournals/rejour/ijpap2k8/ijpap_jul08.asp\#50 7 